\title{
Australian Journal of

\section{Seed cryopreservation, in vitro propagation and ex vitro growth of Cattleya walkeriana Gardner, a vulnerable ornamental orchid}

\author{
Renato Fernandes Galdiano Junior ${ }^{1 *}$, Wagner Aparecido Vendrame ${ }^{2}$, Cristiane Moretto ${ }^{1}$, Ricardo \\ Tadeu de Faria ${ }^{3}$, Eliana Gertrudes de Macedo Lemos ${ }^{1}$
}

\author{
${ }^{1}$ Department of Technology, Univ Estadual Paulista, Faculdade de Ciências Agrárias e Veterinárias, Via de \\ Acesso Prof. Paulo Donato Castellane, s/n, Jaboticabal, SP, 14884-900, Brazil \\ ${ }^{2}$ University of Florida, Tropical Research and Education Center, 18905 SW $280^{\text {th }}$ St, Homestead, FL, 33031- \\ 3314, USA \\ ${ }^{3}$ Universidade Estadual de Londrina, Centro de Ciências Agrárias, Caixa Postal 6001, Londrina, PR, 86051-990, \\ Brazil
}

\section{*Corresponding author: renatofgaldianojr@yahoo.com.br}

\begin{abstract}
The aim of this investigation was to evaluate cryopreservation by vitrification of seeds from the orchid species Cattleya walkeriana and to achieve ex vitro acclimatization of in vitro derived cryopreserved seedlings. Seeds were removed from eight-month-old and ten-month-old capsules, and immersed in LN under different PVS2 exposure times. In in vitro experiment, ten different treatments and five replications with approximately 600 seeds each one were distributed in a completely random design and germination was calculated by the number of germinated seeds developing into protocorms and subsequently into seedlings. Seeds that were immersed directly into LN ( 0 min PVS2) and germinated in $1 / 2$ MS culture medium after plunged directly into LN, returned germination rates of 3.0 (eight-month-old) and 36.8\% (ten-month-old). Ten-month-old seeds in vitrification for $1 \mathrm{~h}$ in PVS2 returned 53\% germination in $1 / 2$ MS culture medium. However, when the same mature seeds were exposed for $1 \mathrm{~h}$ to PVS2 with the addition of $1 \%$ phloroglucinol, germination was $4.36 \%$ higher compared to the treatment without this additive. Seedlings from cryopreserved seeds showed normal development after 210 days of in vitro culture. Seedlings from ten-month-old seeds cryopreserved for $1 \mathrm{~h}$ in PVS2 were acclimatized in greenhouse conditions in either sphagnum moss or sphagnum moss with pine bark (1:1, v/v) revealed the best ex vitro growth. Seed cryopreservation of this orchid species has shown to be efficient, demonstrating the effect of seed maturation time and ex vitro seedling acclimatization was established, with successful development of seedlings.
\end{abstract}

Received 24 Oct 2016; Revised 24 Jan 2017; Accepted 7 March 2017.

Keywords: Acclimatization; germplasm conservation; Orchidaceae; phloroglucinol; vitrification.

Abbreviations: DMSO_Dimethyl sulfoxide; LN_Liquid nitrogen; 1/2 MS_Half-strength Murashige and Skoog culture medium; PVS2_Plant vitrification solution; TCC_2,3,5-triphenyl tetrazolium chloride.

\section{Introduction}

Orchidaceae is one of the three largest families of flowering plants, with more than 800 genera and 25-35,000 species (Arditti 1992). All orchids are listed in Appendix II of the Convention of International Trade in Endangered Species of Wild Fauna and Flora (CITES) (Chugh et al., 2009). Orchids are endangered by a combination of factors: over-collecting for trade as ornamental and medicinal plants, unsuitable agriculture and forestry practices, urbanization, habitat destruction caused by fragmentation or degradation of natural ecosystems, and climate changes that may promote extreme events. Hence, the development of ex situ conservation of orchid germplasm is a promising alternative to protect and conserve native species (Meritt et al., 2014; Popova at al., 2016).

The genus Cattleya Lindley includes orchids native to tropical America (Pridgeon and Morrison 2005), and represents a very important genus for the market due to its high genetic variability, large ability for genetic recombination, and flowers presenting attractive colors, durability, shape, and size. Cattleya walkeriana Gardner is a short-size species native to the Brazilian Central Plateau Savannah (Cerrado) and its beautiful and distinctive flowers (Fig 1A) are quickly regaining popularity worldwide (Menezes 2011). According to the red list of endangered flora species of Brazil, Cattleya walkeriana has very reduced native populations and is considered a vulnerable species especially because of over collection for trade (Ibama 2008). The introduction of this species to genetic breeding may introduce new ornamental resources to floriculture, and also contribute to native population conservation.

Orchid seeds are heterogeneous, and preservation of seeds can help conserve the genetic diversity of plant populations. Thus, seed propagation in wild orchid species has major significance, especially for genetic breeding.

Cryopreservation, an alternative means to conserve plant genetic resources in ultra-low liquid nitrogen temperature ($196{ }^{\circ} \mathrm{C}$ ) is among the most efficient, safe and cost-effective long-term storage techniques for plant materials (Engelmann 2011; Kaviani 2011). Cryopreservation is a suitable biotechnology for preservation of orchid germplasm, 
requiring minimal storage space and maintenance, while ensuring the stability of phenotypic (Vendrame and Faria 2011; Vendrame et al., 2007; 2014) and genotypic characteristics (Hirano et al. 2005; Galdiano et al. 2013; 2014).

Vitrification is defined as the physical process of transition of an aqueous solution into an amorphous phase or glass, while avoiding the formation of crystalline ice. Its usual goal is to achieve intracellular vitrification, whereas avoiding intracellular ice formation and membrane damage (Reed 2008). Vitrification represents a simple and applicable cryopreservation method extensively explored in orchid germplasm storage (Ishikawa et al., 1997; Hirano et al., 2005; Vendrame et al., 2007; Galdiano et al., 2013). Although this technique is very successful, the inclusion of phloroglucinol, a 1,3,5-trihydroxybenzene that has plant growth-promoting activities and potential application to plant tissue culture studies (Teixeira da Silva et al., 2013), has been very promising for increased recovery of vitrified orchid seeds from commercial hybrids (Galdiano et al., 2012) and species (Vendrame and Faria 2011; Galdiano et al., 2013). In vitro grown seedlings often have low or no stomatal activity (due to continuous high humidity) and are grown in a high nutrient environment. The acclimatization procedures are used to gradually decrease relative humidity levels, increase photosynthetic capacity, and acclimate seedlings to low nutrient environments (Kauth et al., 2006). Consequently, the survival rate in the ex vitro environment is low and seedlings survival rate may be low enough to become a limiting factor in the process of in vitro propagation. Therefore, acclimatization is another key to the success of regeneration of seedlings from cryopreserved seeds.

The aim of this investigation was to evaluate cryopreservation by vitrification of seeds from the orchid species Cattleya walkeriana and to achieve ex vitro establishment and acclimatization of in vitro derived seedlings.

\section{Results}

Seed characteristics and germination are summarized in Table 1. Capsules harvested in different maturation times presented seeds with different characteristics of color, viability and germination. Eight-month-old seeds showed white/cream color (Fig 1B), while older seeds revealed brown seeds (Fig 1C). Seed viability $(80 \pm 1.87$, mean \pm standard error), and germination $(81 \pm 0.82)$, were higher in ten-month-old seeds. Moisture content was higher in eightmonth-old seeds $(21 \pm 0.26)$. Seed viability, estimated by TCC test (Fig 1D), and revealed a good correlation with seed germination test

At 120 days after sowing, protocorms started forming seedlings (Fig 1E), and germination percentages were evaluated. The best germination $(53.2 \pm 4.17)$ was observed with ten-month-old seeds dehydrated for $60 \mathrm{~min}$ in PVS2, while the lower germination $(2.8 \pm 0.73)$ was observed with eight-month-old seeds for 0 min in PVS2 (Fig 2). For the control (0 min PVS2), seeds showed a dramatic difference for germination between the different maturation times, whereas ten-month-old seeds showed $36.87 \%$ germination, 12 times higher than the germination of eight-month-old seeds. Furthermore, ten-month-old cryopreserved seeds in PVS2 for $30 \mathrm{~min}$ prior to immersion in $\mathrm{LN}$ showed a germination percentage comparable to that of eight-month-old cryopreserved seeds under the same treatment, showing a dehydration-dependence for enhanced germination.
After 120 min treated with PVS2, seeds decreased germination. Nonetheless, when ten-month old seeds were vitrified for $60 \mathrm{~min}$ in PVS2 with addition of $1 \%$ phloroglucinol, germination increased by $4.36 \%$ (Fig 3).

After 210 days of in vitro culture, seedlings from all treatments developed into normal seedlings with healthy shoot and root formation (Fig 4A). Seedling growth and development was not adversely affected by cryopreservation and no abnormalities were observed.

Hardening of seedlings plantlets in the greenhouse under high humidity conditions (near $80 \%$ ) was found to be critically beneficial for successful acclimatization. Therefore, a great number of seedlings plantlets acclimatized in greenhouse. Among the substrates used, sphagnum moss and the combination of sphagnum moss and pine bark were found to be suitable for $C$. walkeriana in vitro-derived seedlings from cryopreserved seeds for ex vitro establishment and acclimatization in greenhouse conditions (Table 2).

Although pine bark alone showed to be detrimental for seedling survival and seedling height, mixing it in the same proportion with moss supported a good growing substrate, keeping the satisfactory results for the seedling growth and survival (higher than 95\%), number of pseudobulbs and seedling height. Vigorous seedlings will be maintained in greenhouse (Fig 4B) and are expected to bloom within the next years.

\section{Discussion}

Mature seeds of $C$. walkeriana, as other seeds of Orchidaceae family are produced in great number, dust-like in appearance and present a fusiform shape (Arditti and Ghani 2000). Seed viability by the TCC test correlated with seed germination test in previous studies, TTC was consecrated as a seed staining solution for general seed cryopreservation research (Verleysen et al., 2004), as well as for vitrified zygotic embryos (Vanda protocorm-like bodies) (Poobathy et al., 2012). It was also useful for orchid seed cryopreservation (Ishikawa et al., 1997; Hirano et al., 2005; Galdiano et al., 2012). In this study, the TCC test revealed to be safe and a precise test in determining seed viability.

Threated seeds of Vanda coerulea with $33 \%$ of moisture content returned $67 \%$ germination after dehydration for 70 min in PVS2 (Thammasiri and Soamkul 2007). However, when they were directly submitted to LN without dehydration, no germination was observed because of the high seed moisture content. Most of orchid seeds have high moisture content, greater than most plants of agricultural importance (Schwallier et al., 2011). Elevated water content allows lethal damage to cells by intracellular ice nucleation and ice crystal formation after freezing, and may cause physical rupture and mechanical injury to cells (Benson 2008). In this study, seed maturation time seems to be a preponderant factor for seed survival and germination after cryopreservation, as older seeds have lower moisture content than younger seeds, therefore minimizing intracellular ice formation.

In this study, all PVS2 treatments allowed seed germination after cryopreservation. However, germination decreased in those seeds treated for $120 \mathrm{~min}$ in PVS2. Longer periods under vitrification solution may have caused some damage that affected seed embryos.

Plant cell membranes excessively desiccated might suffer structural changes, oxidative stress and protein denaturation (Hoekstra et al., 2001). These could be some of the factors accounting for the decreased germination in seeds treated with PVS2 for $120 \mathrm{~min}$, although additional and more 
Table 1. Seed characteristics of capsules in different maturation times from hand-pollinated Cattleya walkeriana Gardner.

\begin{tabular}{lcc}
\hline & Eight-month-old Capsule $^{\mathrm{a}}$ & Ten-month-old Capsule $^{\mathrm{a}}$ \\
Characteristic & \multicolumn{2}{c}{ Mean $( \pm$ SD) } \\
\hline Moisture $(\%)^{\mathrm{b}}$ & $21 \pm 0.26$ & $16 \pm 0.38$ \\
${\text { Viability (TTC) }(\%)^{\mathrm{c}}}^{\mathrm{c}}$ & $62 \pm 1.4$ & $80 \pm 1.87$ \\
${\text { Germination }(\%)^{\mathrm{c}}}^{\mathrm{c}}$ & $56 \pm 2.48$ & $81 \pm 0.82$ \\
\hline${ }^{\mathrm{a}}$ Three different capsules were evaluated. ${ }^{\mathrm{b}}$ Values are mean of five replic ations of $50 \mathrm{mg}$ seeds each. ${ }^{\mathrm{c}}$ Values are mean of five replications with 600 seeds each.
\end{tabular}
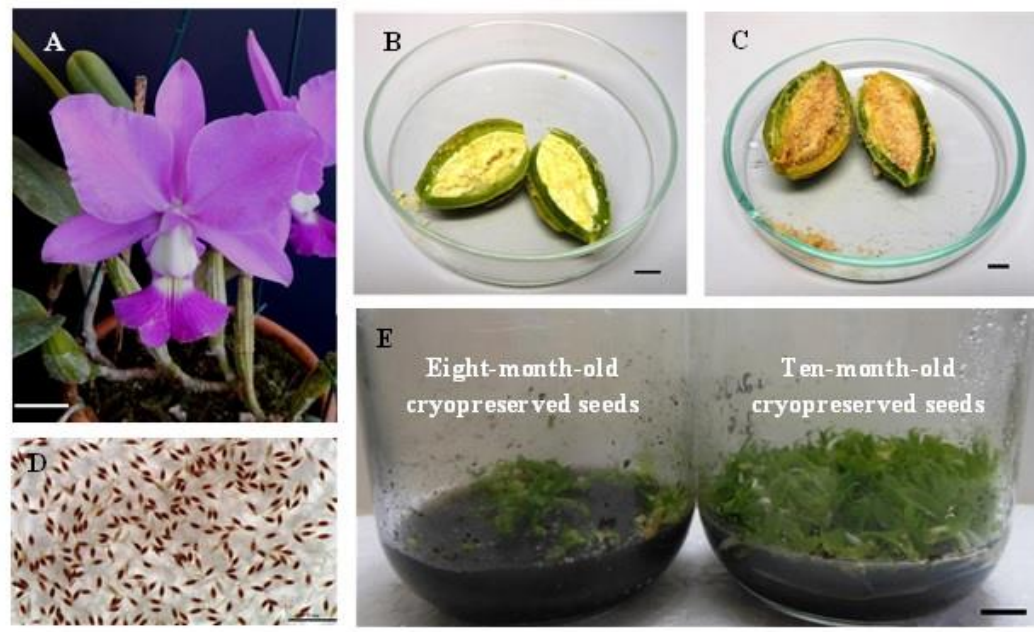

Fig 1. Cattleya walkeriana Gardner inflorescence, seeds and germinated seedlings. (A) The inflorescence general aspect, bar $2.5 \mathrm{~cm}$. (B) Seeds of eight-month-old and (C) ten-month-old capsules, bars $1.0 \mathrm{~cm}$. (D) Stained seeds of ten-month-old capsules. bar $1.0 \mathrm{~mm}$.

(E) Seedlings at 120 days after sowing from cryopreserved seeds at 0 min PVS2, bar $1.0 \mathrm{~cm}$.

Table 2. Effect of different substrates on ex vitro establishment and acclimatization of cryopreserved seed-derived Cattleya walkeriana Gardner seedlings after 150 days in greenhouse conditions

\begin{tabular}{lccc}
\hline Treatments & Survival $(\%)$ & No. of pseudobulbs & Seedling height $(\mathrm{cm})$ \\
\hline Moss & $98 \mathrm{a}$ & $3.98 \mathrm{a}$ & $6.64 \mathrm{a}$ \\
Moss and Pine bark $(1: 1, \mathrm{v} / \mathrm{v})$ & $96 \mathrm{a}$ & $3.72 \mathrm{a}$ & $6.76 \mathrm{a}$ \\
Pine bark & $74 \mathrm{~b}$ & $3.86 \mathrm{a}$ & $3.54 \mathrm{~b}$ \\
\hline
\end{tabular}

In each treatment, 50 seedlings were used. Values with different letters are significantly different according to Tukey's test after square root and arcsine transformation (P < $0.05)$.

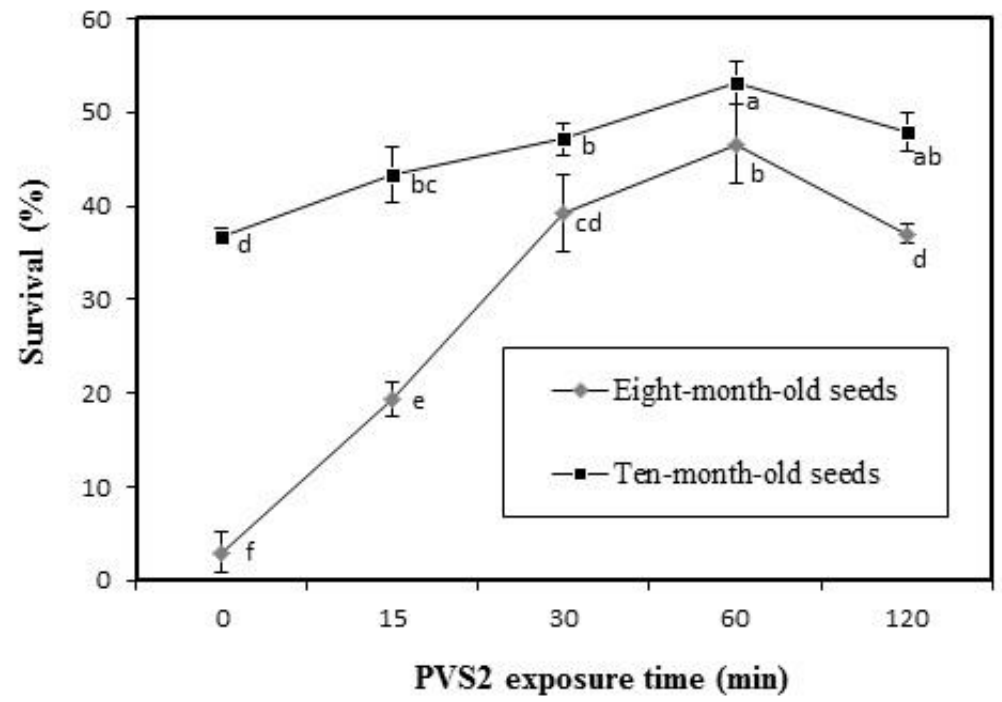

Fig 2. Germination percentage of eight-month-old and ten-month-old Cattleya walkeriana seeds after cryopreservation by vitrification under different exposure times to PVS2. Seeds were cryopreserved in LN for $1 \mathrm{~h}$. Values with different letters are significantly different according to Tukey's test after square root and arcsine transformation $(\mathrm{P}<0.05)$. Approximately 600 seeds were used in each of the five replications. Bars indicate standard error. 


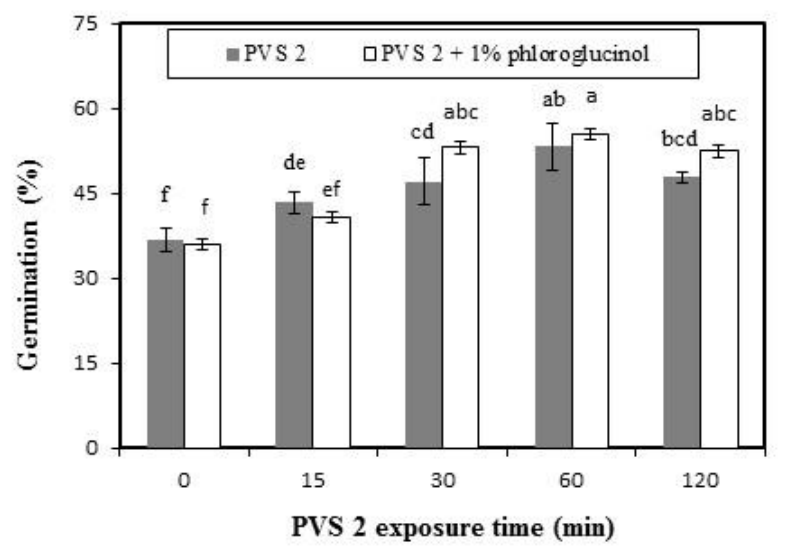

Fig 3. Germination percentage of ten-month-old Cattleya walkeriana mature seeds after cryopreservation by vitrification under different exposure times to PVS2 and PVS2 $+1 \%$ phloroglucinol. Seeds were cryopreserved in LN for $1 \mathrm{~h}$. Values with different letters are significantly different according to Tukey's test after square root and arcsine transformation $(\mathrm{P}<0.05)$. Approximately 600 seeds were used in each of the five replications. Bars indicate standard error.
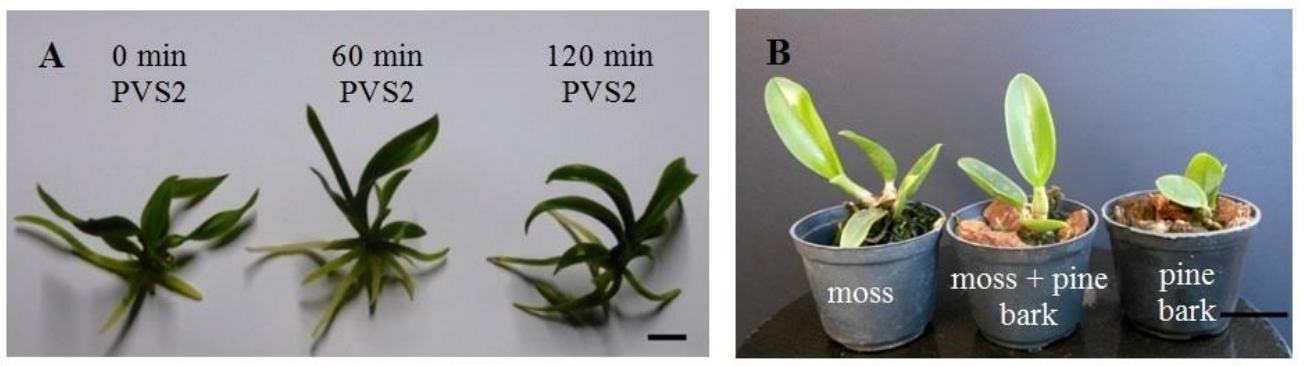

Fig 4. In vitro developed and ex vitro acclimatized seedlings of Cattleya walkeriana from cryopreserved seeds. (A) Seedlings raised after 210 days of in vitro culture, bar $1.0 \mathrm{~cm}$; (B) Seedlings acclimatized in different substrates, bar $5.0 \mathrm{~cm}$.

detailed studies would be necessary to determine specific factors. Eight-month-old seeds treated with PVS2 with $1 \%$ phloroglucinol for $60 \mathrm{~min}$ had a slight increase in germination. Phloroglucinol has been used to improve the recovery of cryopreserved orchid seeds for Dendrobium hybrid (Galdiano et al., 2012) and Oncidium flexuosum (Galdiano et al., 2013), and also for Dendrobium nobile protocorms (Vendrame and Faria 2011). Such studies using phloroglucinol as an additive to PVS2 demonstrated a significant increase in germination of seeds and recovery of protocorms after cryopreservation.

The natural habitat for Cattleya orchid species include hot and humid areas in Central and South Americas, generally near a river or other water sources (Pridgeon and Morrison 2005). Therefore, hardening conditions in this study provided a proper environment for the successful acclimatization and growth of plantlets. In addition, a good growing substrate for Cattleya species must have the attributes of good porosity, water holding capacity, and drainage for epiphytic orchids, such as for C. walkeriana (Menezes 2014). In this study, mixing pine bark and moss in equal proportions was essential to allow the high survival observed, with subsequent successful growth and development of seedlings.

\section{Materials and Methods}

Plant material, capsule sterilization and seed viability assessment

Eight-month-old and ten-month-old mature seed capsules of hand-pollinated Cattleya walkeriana obtained from greenhouse grown of seven-year-old plants were used.
Capsules were surface disinfected in a laminar flow hood using ethanol $70 \%$ for $5 \mathrm{~min}$, followed by $1 \%$ sodium hypochlorite (Clorox Ltda., Brazil) for $30 \mathrm{~min}$, and washed three times in sterile distilled water. Capsules were dried in the laminar flow hood and dissected longitudinally with forceps and surgical blade. Seed moisture content evaluation was performed according to Vendrame et al., (2007). About $50 \mathrm{mg}$ of seeds contained approximately 600 seeds. Seeds were maintained in $2-\mathrm{mL}$ cryovials. The viability was assessed using a modified 2,3,5-triphenyl tetrazolium chloride (TTC) test with sucrose (Hosomi et al., 2012). Five cryovials were used for each treatment. Seeds were counted using a Leica MZ12.5 stereoscope, and only rose-red seeds were counted as viable. A seed germination test was performed in semi-solid $1 / 2$ MS medium containing $0.088 \mathrm{M}$ sucrose ( $\mathrm{pH}$ 5.7), and cultured under controlled environmental conditions $\left(26 \pm 2{ }^{\circ} \mathrm{C} ; 60 \mu \mathrm{mol} \mathrm{m}{ }^{-2} \mathrm{~s}^{-1} ; 14 / 8\right.$ light/dark; 4x 9A Phillips ${ }^{\circledR}$ fluorescent bulbs) to verify the seed viability.

\section{Osmoprotection and seed cryopreservation treatments}

For each treatment, $1 \mathrm{~mL}$ cryoprotective loading solution was added, consisting of $2.0 \mathrm{M}$ glycerol and $0.4 \mathrm{M}$ sucrose (Nishizawa et al. 1993). Cryovials were left for $20 \mathrm{~min}$ at room temperature $\left(26 \pm 2{ }^{\circ} \mathrm{C}\right)$ prior to the addition of a plant vitrification solution (PVS2). The PVS2 (Sakai et al. 1990) contains $30 \%(\mathrm{w} / \mathrm{v})$ glycerol, $15 \%(\mathrm{w} / \mathrm{v})$ ethylene glycol, and $15 \%(\mathrm{w} / \mathrm{v})$ dimethyl sulfoxide (DMSO) in $1 / 2 \mathrm{MS}$ medium containing $0.4 \mathrm{M}$ sucrose ( $\mathrm{pH}$ 5.7).

The effect of different exposure times $(0,15,30,60$ and $120 \mathrm{~min}$ ) in PVS2 at $0^{\circ} \mathrm{C}$ was assessed for seed germination. 
The control consisted of direct exposure of seeds to liquid nitrogen - LN (time 0 min) without PVS2 solution.

After $60 \mathrm{~min}$ in LN, cryovials were removed and rapidly rewarmed in a $40{ }^{\circ} \mathrm{C}$ water bath for $90 \mathrm{~s}$. Cryopreservation solutions were removed from cryovials with a sterile disposable transfer pipette under a laminar flow hood. Seeds were rinsed with liquid $1 / 2 \mathrm{MS}$ culture medium $+1.2 \mathrm{M}$ sucrose (pH 5.7) for $15 \mathrm{~min}$, transferred to $280-\mathrm{mL}$ flasks containing $40 \mathrm{~mL}$ semi-solid $1 / 2$ MS medium $+3 \%$ sucrose and $2 \mathrm{~g} \mathrm{~L}^{-1}$ activated charcoal ( $\mathrm{pH}$ 5.7), sealed with PVC film (Dispafilm Ltda., Brazil) and cultured under controlled environmental conditions as described above. Treatments were comprised of five replicates with 600 seeds each. Petri dishes were visually monitored weekly for germination occurrence. Germination percentage was assessed after 120 days for the control and the different treatments by counting the number of germinated seeds under a Leica MZ12.5 stereoscope. Seed survival was assessed by counting the number of germinated seeds that formed protocorms.

\section{Seed cryopreservation with phloroglucinol}

Seeds of ten-month-old capsules were used in further experiments to test the effect of phloroglucinol as an additive to PVS2 solution. Treatments comprised of different exposure times $(0,15,30,60$ and $120 \mathrm{~min})$ in PVS2 with or without $1 \%$ phloroglucinol at $0^{\circ} \mathrm{C}$ were assessed for seed germination. Seeds $(50 \mathrm{mg})$ in cryovials were osmoprotected in $1 \mathrm{~mL}$ of load solution for $20 \mathrm{~min}$, dehydrated in the PVS2 treatments and plunged directly into $\mathrm{LN}$ for $60 \mathrm{~min}$. After cryopreservation, cryovials were rewarmed in a $40{ }^{\circ} \mathrm{C}$ water bath for $90 \mathrm{~s}$ and seeds were rinsed with liquid $1 / 2$ MS culture medium $+1.2 \mathrm{M}$ sucrose $(\mathrm{pH}$ 5.7) for $15 \mathrm{~min}$. Sowing and flask incubation conditions used were the same as described above.

\section{Protocorm in vitro growth and seedling development}

Seedlings from protocorms developed from cryopreserved seeds were transferred to $280 \mathrm{~mL}$ flasks containing $40 \mathrm{~mL}$ of semi-solid $1 / 2$ MS culture medium for further growth and development. Flasks were maintained for 90 days under the same conditions as described above. At 210 days of culture, fully developed seedlings were formed.

\section{Seedling acclimatization and hardening in greenhouse}

Well-developed seedlings from each treatment were washed thoroughly under tap water for 1-1.5 min to remove traces of agar-gelled medium adhered to them. Uniform seedlings from cryopreserved seeds (PVS2 for $60 \mathrm{~min}$ ) were transferred to individual $6 \mathrm{~cm}$ plastic pots $(120 \mathrm{~mL}$ per pot) containing sphagnum moss (Five Star, Chile) or sphagnum and pine bark (Agrolink Ltda., Brazil) $(1: 1, \mathrm{v} / \mathrm{v})$ or pine bark as the growing substrate. Each treatment consisted of 50 seedlings that were left in a greenhouse with $70 \%$ shade, $80 \%$ humidity and watered every day (50 mL of tap water per pot). Seedlings were sprayed every other week with Plant Prod (Plant Products, Canada) solution consisting of 35\% total N, $5 \% \mathrm{P}_{2} \mathrm{O}_{5}$ and $10 \% \mathrm{~K}_{2} \mathrm{O}$ and Calbit-C (Valagro, Italy), in a concentration of $2 \mathrm{ml} \quad \mathrm{L}^{-1}, 20 \mathrm{~mL}$ per seedling. At 150 days after acclimatization, seedling survival, number of pseudobulbs and seedling height were recorded.

\section{Experimental design and data analysis}

For cryopreservation experiment, ten different treatments of $0,15,30,60$ and $120 \mathrm{~min}$. on PVS2 with or without phloroglucinol and five replicates of 600 seeds each treatment. Germination percentage was calculated by the number of germinated seeds developing into protocorms and subsequently into seedlings of the total viable seed evaluated. For seedlings hardening in greenhouse experiment, biometric data were evaluated of 50 seedlings analyzed per treatment. All experiments were arranged in a completely randomized design (CRD). The data were subjected to analysis of variance (ANOVA) using software $\mathrm{R}$, and means were separated by Tukey's test $(P<0.05)$. Seed germination data were normalized using the square root and arcsine transformation.

\section{Conclusion}

In this study, seed cryopreservation of the native vulnerable orchid Cattleya walkeriana was achieved. Seed maturation time seems to be a preponderant factor for survival and germination after cryopreservation. Ten-month-old seeds dehydrated in PVS2 at $0^{\circ} \mathrm{C}$ for 60 min had better germination compared with eight-month-old seeds, presenting considerable germination even without dehydration and plunged directly in LN (control). However, when older seeds were vitrified for 60 min with PVS2 with $1 \%$ phloroglucinol, germination increased by $4.36 \%$ compared with the treatment without this additive. Seedlings of all treatments developed into normal seedlings with healthy shoot and root formation, and could be acclimatized under ex vitro conditions on different substrates, such as sphagnum moss or sphagnum moss + pine bark. Seed long-term storage and successful establishment in greenhouse of in vitro derived seedlings could assist in the species future reintroduction efforts back to their natural habitat, as well as for large-scale cultivation for commercial purposes. Furthermore, this technique can be a valuable tool for breeding programs of Cattleya aiming at desired characteristics.

\section{Acknowledgments}

The authors wish to thank Fapesp (Proc. № 2014/17896-0) and $\mathrm{CNPq}$ (Proc. $\mathrm{N}^{\circ}$ 150214/2015-4) for supporting this study.

\section{References}

Arditti J (1992) Fundamentals of orchid biology. John Willey and Sons, New York, pp. 55-100.

Arditti J, Ghani AKA (2000) Numerical and physical properties of orchid seeds and their biological implications. New Phytol. 145:367-421.

Benson EE (2008) Cryopreservation theory. In: Reed BM (ed) Plant cryopreservation: a practical guide. Springer, New York, pp. 15-32.

Chugh S, Guha S, Rao IU (2009) Micropropagation of orchids: a review on the potential of different explants. Sci Hort. (Amst) 122:507-520.

Engelmann F (2011) Use of biotechnologies for the conservation of plant biodiversity. In Vitro Cell Dev Biol Plant. 47(1):5-16.

Galdiano RF Jr, Lemos EGM, Faria RT, Vendrame WA (2012) Cryopreservation of Dendrobium hybrid seeds and protocorms as affected by phloroglucinol and Supercool X1000. Sci Hort. (Amst) 148:154-160.

Galdiano RF Jr, Lemos EGM, Vendrame WA (2013) Cryopreservation, early seedling development, and genetic stability of Oncidium flexuosum Sims. Plant Cell Tiss Organ Cult. 114(1):139-148. 
Galdiano RF Jr, Lemos EGM, Faria RT, Vendrame WA (2014) Seed development and evaluation of genetic stability of cryopreserved Dendrobium hybrid mature seeds. Appl Bioch Biotech. 172(5):2521-2529.

Hirano T, Godo T, Mii M, Ishikawa K (2005) Cryopreservation of immature seeds of Bletilla striata by vitrification. Plant Cell Rep. 23: 534-539.

Hoekstra FA, Golovina EA, Buitink J (2001) Mechanisms of plant desiccation tolerance. Trends Plant Sci. 6:431-438.

Hosomi ST, Custodio CC, Seaton PT, Marks TR, MachadoNeto NB (2012) Improved assessment of viability and germination of Cattleya (Orchidaceae) seeds following storage. In Vitro Cell Dev Biol Plant. 48:127-136.

Ishikawa K, Harata K, Mii M, Sakai A, Yoshimatsu K, Shimomura K (1997) Cryopreservation of zygotic embrios of Japaneses terrestrial orchid (Bletilla striata) by vitrification. Plant Cell Rep. 16(11):754-757.

Kauth PJ, Dutra D, Johnson TR, Stewart SL, Kane ME, Vendrame WA (2006) Techniques and applications of in vitro orchid seed germination. In: Teixeira da Silva J (ed) Floriculture, Ornamental and Plant Biotechnology: Advances and Topical Issues, v. V, Global Science Books, Iselworth, pp.375-391.

Kaviani B (2011) Conservation of plant genetic resources by cryopreservation. Aust J Crop Sci. 5(6):778-800.

Ibama (Brazilian Institute of Environment and Renewable Resources, Ministry of Envieronment). 2008. Lista Oficial das Espécies da Flora Ameaçada de Extinção (Anexo I) e Lista Oficial da Flora Brasileira com Deficiências de Dados. Diário Oficial da União, Brasília, DF, Brasil, 24 set. 2008. Available

at: <http://www.mma.gov.br/estruturas/ascom_boletins/_arqui vos/83_19092008034949.pdf.> Accessed on September 25, 2016.

Menezes LC (2011) Cattleya walkeriana. Ibama, Brasília, 183.

Menezes LC (2014) Orchids: Brazilian central plateau. Ibama, Brasília, 226.

Meritt DJ, Hay FR, Swarts ND, Sommerville, KD, Dixon KW (2014) Ex situ conservation and cryopreservation of orchid germplasm. Int J Plant Sci. 175(1):46-58

Nishizawa S, Sakai A, Amano Y, Matuzawa T (1993) Cryopreservation of asparagus (Asparagus officinalis L.) embryogenic suspension cells and subsequent plant regeneration by vitrification. Plant Sci. 91(1):67-73.

Poobathy R, Hesan NA, Julkifle AL, Subramanuam S (2012) Vitrification and histological analyses of protocorm-like bodies of Vanda Kaseem's Delight orchid. Aust J Crop Sci. 6(2):219-224.

Popova E, Kim HH, Saxena PK, Engelmann F, Pritchard HW (2016) Frozen beauty: the cryobiotechnology of orchid diversity. Biotech Adv. 34(4):380-403.

Pridgeon A, Morrison A (2005) The illustrated encyclopedia of orchids: over 1100 species illustrated and identified, v.1. Timber Press, Portland.
Reed BM (2008) Cryopreservation - practical considerations. In: Reed, BM (ed) Plant cryopreservation: a practical guide. Springer, New York, pp. 3-14.

Sakai A, Kobayashi S, Oiyama I (1990) Cryopreservation of nucelar cells of navel orange (Citrus cinensis Osb. var. brasiliensis Tanaka) by vitrification. Plant Cell Rep. 9(1):30-33.

Schwallier R, Bhoopalan V, Blackman S (2011) The influence of seed maturation on desiccation tolerance in Phalaenopsis amabilis hybrids. Sci Hort. (Amst) 128:136140.

Thammasiri K, Soamkul L (2007) Cryopreservation of Vanda coerulea Griff. ex Lindl. seeds by vitrification. Sci Asia 33:223-227.

Teixeira da Silva JA, Dobranszki J, Ross S (2013) Phloroglucinol in plant tissue culture. In Vitro Cell Dev Biol Plant. 49(1):1-16.

Vendrame WA, Carvalho VS, Dias JMM (2007) In vitro germination and seedling development of cryopreserved Dendrobium hybrid mature seeds. Sci Hort. (Amst) 114:188-193.

Vendrame WA, Carvalho VS, Dias JMM, Maguire I (2008) Pollination of Dendrobium hybrids using cryopreserved pollen. HortScience. 43(1): 264-267.

Vendrame WA, Faria RT (2011) Phloroglucinol enhances recovery and survival of cryopreserved Dendrobium nobile protocorms. Sci Hort. (Amst) 128:131-135.

Vendrame WA, Faria RT, Sorace M, Sahyun SA (2014) Orchid cryopreservation. Ciênc Agrotec. 38(3):213-229.

Verleysen H, Samyn G, Van Bockstaele E, Debergh P (2004) Evaluation of analytical techniques to predict viability after cryopreservation. Plant Cell Tiss Org Cult. 77(1):11-21. 